\title{
A TENSÃO ENTRE DEMOCRACIA E CONSTITUCIONALISMO: MOVIMENTOS DE 7 DE SETEMBRO DE 2021.
}

\author{
Thiago Cipriani
}

\section{Resumo:}

Este trabalho materializa a pesquisa sobre a suposta tensão existente entre democracia e constitucionalismo, levando em consideração os movimentos populares ocorridos no Brasil no dia 7 de setembro de 2021, onde milhares de pessoas foram às ruas em apoio ao Presidente da República, buscando a intervenção do Executivo nos outros Poderes, modificações no processo eleitoral etc. Utilizou-se o método indutivo, com análises bibliográficas e documentais, tomando-se com marco teórico a teoria constitucional clássica e contemporânea. A hipótese é que não há contradição entre democracia e constitucionalismo, mas complementaridade.

Palavras-chave: Democracia, Soberania Popular, Constitucionalismo, Poder Constituinte, Constituição.

\section{THE TENSION BETWEEN DEMOCRACY AND CONSTITUTIONALISM: MOVEMENTS OF SEPTEMBER 7, 2021.}

\begin{abstract}
:
This work materializes the research on the supposed tension between democracy and constitutionalism, taking into account the popular movements that took place in Brazil on September 7, 2021, where thousands of people took to the streets in support of the President of the Republic, seeking the intervention of the Executive in other Powers, changes in the electoral process, etc. The inductive method was used, with bibliographic and documental analysis, taking classical and contemporary constitutional theory as a theoretical framework. The hypothesis is that there is no contradiction between democracy and constitutionalism, but complementarity.
\end{abstract}

Keywords: Democracy, Popular Sovereignty, Constitutionalism, Constituent Power, Constitution.

\section{INTRODUÇÃO}

Este trabalho materializa os resultados da pesquisa bibliográfica sobre conceitos nucleares do Direito Constitucional, notadamente constitucionalismo e democracia, objetivando-se analisar a aparente tensão existente entre ambos, haja vista que o primeiro pode ser preliminarmente conceituado como o conjunto de direitos fundamentais do homem e conjunto de normas fundantes do Estado, e o segundo como categoria representativa da soberania popular. 
A pesquisa partiu de uma análise da teoria clássica de matriz europeia, trazendo pensadores como Bobbio, Habermas, Kelsen, Hesse e outros, para em seguida avançar em direção ao estudo do tema sob uma perspectiva latino-americana, entendendo os conceitos a partir de uma visão pluralista da cultura jurídica.

O trabalho foi subdividido em três tópicos de argumentos, sendo individualmente analisados os conceitos de democracia e constitucionalismo e, após, evoluiu-se para a análise de uma possível tensão existente entre ambos, inclusive a partir da análise do evento ocorrido no Brasil no último dia sete de setembro.

O referido evento representa um levante popular, onde milhões de pessoas, conclamadas pelo Presidente da República Jair Messias Bolsonaro, foram às ruas em defesa de pautas como a intervenção nos poderes legislativo e judiciário, alteração do processo eleitoral etc.

A hipótese preliminar é de que inexiste contradição entre constitucionalismo e democracia. Tratam-se, na verdade de conceitos complementares, sendo um pressuposto do outro, notadamente porque não se pode simplificar o conceito de democracia como governo da maioria (MATTEUCCI, 1998). O constitucionalismo estabelece as regras do jogo para o exercício da democracia, garantindo-se os direitos da maioria e também das minorias, onde estão os oprimidos, marginalizados etc.

É certo que a bibliografia pesquisada não esgota o tópico proposto, principalmente por tratar-se de tema que comporta longa e profícua discussão desde a antiguidade clássica, na Grécia. Inobstante a origem dos conceitos de constitucionalismo e democracia, a pesquisa iniciou com a exposição dos conceitos a partir das Revoluções Francesa e Americana estendendo-se até a doutrina atual.

\section{AS FACES DA DEMOCRACIA DESDE A REVOLUÇÃO FRANCESA ATÉ O PENSAMENTO DO PLURALISMO JURÍDICO LATINO-AMERICANO.}

O presente trabalho parte de conceitos de democracia sob uma perspectiva eurocêntrica, tendo em vista a necessidade de compreender a categoria de forma ampla, mas objetiva alcançar uma análise a partir da realidade local e sem as distorções decorrentes da simples importação de conceitos desconexos da realidade brasileira. 
A análise parte de um dos pensadores do iluminismo, onde a vontade democrática decorria do rompimento com o absolutismo. Rousseau conceituava democracia como a forma de governo em que a vontade do povo e do soberano caminhassem no mesmo sentido e representassem um único interesse. Segundo o autor:

Teria desejado nascer em um país onde o soberano e o povo pudessem ter apenas um único e mesmo interesse, para que todos os movimentos da máquina se dirigissem sempre para a felicidade de todos. Não sendo isto possível, a menos que povo e soberano fossem uma só pessoa, conclui-se que eu desejaria ter nascido sob um governo democrático sabiamente constituído (ROUSSEAU, 1989, p. 29).

Ainda segundo Rousseau, a democracia é a forma de governo que traz mais igualdade e menos se distancia do estado de natureza do ser humano, pressupondo que o poder é proporcionalmente distribuído. Faz essa análise quando compara a monarquia, a aristocracia e a democracia:

As diversas formas de governo encontram sua origem nas diferenças mais ou menos profundas que existiram entre os particulares no momento da instituição. Se um homem era eminente pelo poder, pela virtude, pela riqueza ou pelo crédito, só ele foi eleito magistrado, e o Estado tornou-se monárquico. Se vários homens, quase iguais entre si, prevaleciam sobre todos os outros e foram eleitos conjuntamente, teve-se uma aristocracia. Aqueles cuja fortuna ou talentos eram menos desproporcionais, e que menos haviam se distanciado do estado de natureza, conservaram em comum a administração suprema e formaram uma democracia. (ROUSSEAU, 1989, p. 109).

Entretanto, para o autor, a democracia verdadeira é aquela em que as decisões são tomadas diretamente pelo povo, o que, segundo ele, normalmente não acontece por falta de tempo, estrutura e comodidade (ROUSSEAU, 1982, p. 25). Nesse contexto, Rousseau entendia a democracia como o governo pelo povo, mas considerava que o próprio povo renuncia a esta prerrogativa em favor do governante por motivos diversos.

Muitos anos depois, no início do século XX, Kelsen, famoso por sua obra "Teoria Pura do Direito", muito criticado e às vezes até mesmo mal interpretado, tendo em vista a defesa do positivismo jurídico e a análise do direito como norma pura, despida de ideologias, possui uma obra intitulada "A Democracia", onde analisa que nos Estados modernos vige a democracia indireta, que é caracterizada como democracia parlamentar, onde a vontade do 
povo é exercida através de seus representantes eleitos através do direito de voto (KELSEN, 2000). Por isso, a democracia pressupõe a união de indivíduos através da afinidade do pensamento político. Portanto, para Kelsen:

[...] a democracia só poderá existir se os indivíduos se agruparem segundo suas afinidade políticas, com o fim de dirigir a vontade geral para os seus fins políticos, de tal forma que, entre o indivíduo e o Estado, se insiram aquelas formações coletivas que, como partidos políticos, sintetizem as vontades de cada um dos indivíduos. (KELSEN, 2000, p. 40)

$\mathrm{Na}$ obra fica clara sua predileção por um sistema democrático, denominando a democracia como um ponto de equilíbrio do poder político. Em suas palavras "a democracia é o ponto de equilíbrio para o qual sempre deverá voltar o pêndulo político, que oscila para a direita e para a esquerda" (KELSEN, 2000, p. 78). Se posicionando em relação à ideia de democracia no marxismo, Kelsen defende que a democracia é a única forma política de defender o conflito de classes, afirmando que:

E, se há uma forma política que ofereça a possibilidade de resolver pacificamente esse conflito de classes, deplorável mas inegável, sem levá-lo a uma catástrofe pela via cruenta da revolução, essa forma só pode ser a da democracia parlamentar, cuja ideologia é sim, a liberdade não alcançável na realidade social, mas cuja realidade é a paz. (KELSEN, 2000, p. 78)

Portanto, para Kelsen a democracia é a prevalência da vontade geral, que cria o Estado, obrigando o indivíduo a obedecer este ente ficto, e, por consequência, ter, através dele, sua liberdade concretizada.

Na mesma toada de Kelsen, Bobbio entende que o exercício do poder pelo povo se dá de forma indireta, acrescentando que na teoria política contemporânea a definição tende a seguir o seguinte procedimento universal:

na teoria política contemporânea mais em prevalência nos países de tradição democrático-liberal. As definições de Democracia tendem a seguir procedimentos universais: 1) órgão político máximo, que deverá conter membros eleitos direta ou indiretamente pelo povo; 2) outras instituições com dirigentes eleitos, como os órgãos da administração local ou o chefe de Estado; 3) todos os cidadão que atingiram a maioridade sem nenhuma distinção devem ser eleitores; 4) todos eleitores devem ter voto igual; 5) Todos eleitores devem ser livres de votar segundo a própria opinião formada; 6) devem ser livres também no sentido em que devem ser postos 
em condição de ter reais alternativas (o que exclui como democrática qualquer eleição de lista única ou bloqueada); 7) para as eleições dos representantes como para as decisões do órgão político supremo vale o principio da maioria numérica, se bem que podem ser estabelecidas várias formas de maioria segundo critérios de várias formas de oportunidade não definidos de uma vez para sempre; 8) nenhuma decisão tomada por maioria deve limitar os direitos da minoria, de um modo especial o direito de tornarse maioria, em paridade de condições; 9) o órgão do Governo deve gozar de confiança do Parlamento ou do chefe do poder executivo, por sua vez, eleito pelo povo. (BOBBIO, 2000, p.327-328).

Estas regras analisam como se deve chegar à decisão democrática política, o que ocorre a partir do agir democrático. Assim, conclui-se que o autor defende a democracia como um conjunto de regras e que ela deve ser representativa, pois, dada a complexidade da sociedade, não há como ser feita de forma direta.

Habermas (2000), por sua vez, conceitua democracia a partir de sua teoria do agir comunicativo, onde os sujeitos possuem autonomia e autoridade de consciência e são atores dos processos legislativos, bem como, ao mesmo tempo, sofrem as coerções deste processo como num efeito reflexivo.

A teoria do discurso sugere o exercício da democracia através da intersubjetividade de cada cidadão, bem como seu aparato cultural, técnico, sociológico e outros, irão determinar a norma democraticamente, de modo que a referida teoria

[...] não condiciona o sucesso da política deliberativa a um corpo de cidadãos capaz de agir coletivamente, mas a uma institucionalização de procedimentos e pressupostos comunicativos correspondentes, bem como à interação entre deliberações institucionalizadas e opiniões públicas geradas de maneira informal. A procedimentalização da soberania popular e o reacoplamento do sistema político nas redes periféricas da esfera pública e política andam juntos com a imagem de uma sociedade descentralizada. (Habermas, 2020, p.381-382).

Desse modo, no procedimentalismo habermasiano as ações são realizadas através dos processos de entendimento dos atores numa rede de comunicação entre esfera pública, social, econômica e política. Os consensos e dissensos, que serão convencionados pela sociedade participativa, irão ser transformados em legislação que será aplicada nas esferas públicas e administrativas. 
A leitura desses conceitos leva a conclusão de que a democracia se concretiza através de diferentes procedimentos de participação direta e indireta do povo no governo. Entretanto, no contexto brasileiro e latino-americano, a importação de qualquer desses conceitos demonstra-se problemática, tendo em vista as diferenças sociais e culturais advindas do processo de colonização.

Em contraponto a esta versão eurocêntrica de democracia até então exposta, Wolkmer e Ferrazzo (2020) tratam o tema sob uma abordagem decolonial, sugerindo conceitos como o da democracia comunal desenvolvida na Venezuela e da democracia comunitária desenvolvida na Bolívia.

Lança-se uma crítica à visão de democracia desenvolvida na Europa a partir das revoluções burguesas, que estabeleceram um paradigma político reforçado por discursos padrões de uma sociedade que traça um ideal de civilidade. Esta visão ocidental de democracia é representada por um padrão hegemônico que se estabelece através de um modelo de representação, que pressupõe um apurado nível de igualdade entre os atores do processo democrático (WOLKMER e FERRAZZO, 2020, p. 69).

Esta decolonialização cultural e mudança do conceito de democracia é lançado a partir de um movimento denominado de "Novo Constitucionalismo" ou, como é conhecido, "Constitucionalismo Latino-americano", que inaugura uma ideia pautada no pluralismo jurídico, respeitando a ideologia e o direito dos povos nativos.

Referindo-se aos modelos de democracia boliviano e venezuelano, Wolkmer e Ferrazzo (2020, p. 70-71) afirmam que entre ambos existem similaridades e distinções, realizando uma análise dos modelos a partir de elementos dogmáticos e aportes interdisciplinares. Exemplificam afirmando que a democracia na Bolívia

em suas dimensões jurídica, social e ontológica, articula elementos como terra, território, autonomia e cosmovisão, numa relação indissolúvel que lhe dá sentido, um sentido que não pode ser explicado abstratamente, como se pode fazer - e de fato se faz - no campo dogmático-científico do direito positivo (WOLKMER; FERRAZZO, 2020, p. 71).

A democracia, nesse contexto, é vivenciada nas relações comunitárias e assembleias diversas, não constituindo um diálogo de iguais, justamente porque expressa uma relação de sujeitos e realidades distintas (WOLKMER; FERRAZZO, 2020, p. 77). 
$\mathrm{Na}$ Venezuela, a Constituição bolivariana traz uma série de exemplos de instituição da soberania popular como esforço para a sua efetivação material. A referida Constituição valoriza decisões tomadas pelos cidadãos, estabelecendo-as como vinculantes, enaltece o protagonismo popular através do incentivo dos princípios da cooperação, solidariedade e autogestão (WOLKMER; FERRAZZO, 2020, p. 80).

Portanto, sob esse viés decolonial, a ideia de democracia pressupõe o reconhecimento de desigualdades culturais e sociais estabelecidas em razão do processo de colonização europeia na América-latina, que resultou na exclusão dos povos originários e estabelecimento de um sistema discriminatório dos pobres e das minorias, de modo que a democracia somente se materializa efetivamente a partir de instrumentos que permitam a efetiva participação desses excluídos.

\section{O CONSTITUCIONALISMO: DO MOVIMENTO MODERNO AO NOVO CONSTITUCIONALISMO LATINO-AMERICANO.}

A ideia da existência de normas dotadas de superioridade em relação às outras, estabelecendo limites à ação dos governantes é antiga e pode ser encontrada, inclusive no Antigo Testamento e na Grécia antiga (BARCELOS, 2020).

As revoluções Francesa e Americana constituem importantes e decisivos movimentos da histórica do constitucionalismo, fundando o constitucionalismo moderno, que representa "uma técnica específica de limitação de poder com fins garantísticos" (CANOTILHO, 2002, p. 51), tendo como características principais a separação dos poderes, limitação da vontade do monarca e garantias aos direitos individuais.

Segundo Barroso (2019, p. 131), o poder constituinte "é limitado pela cosmovisão da sociedade - suas concepções sobre ética, dignidade humana, justiça, igualdade, liberdade e pelas instituições jurídicas necessárias à sua positivação."

Estas concepções sociais, porém, são dinâmicas e mutáveis, de modo que a Constituição, além de manter a ordem jurídica estabelecida pelo constituinte, precisa ser dotada de certo grau de flexibilidade, com o objetivo de manter-se atual aos anseios do povo (BARROSO, 2019, p. 132).

Para Canotilho (1993, p. 91), 
[...] o poder constituinte, na teoria de Sieyès, seria um poder inicial, autónomo e omnipotente. É inicial porque não existe, antes dele, nem de facto nem de direito, qualquer outro poder. É nele que se situa, por excelência, a vontade do soberano (instância jurídico-política dotada de autoridade suprema). É um poder autónomo: a ele e só a ele compete decidir se, como e quando, deve 'dar-se' uma constituição à Nação. É um poder omnipotente, incondicionado: o poder constituinte não está subordinado a qualquer regra de forma ou de fundo.

Nesse contexto, o Poder Constituinte desde a França do final do século XVII, é visto como um poder inicial, autônomo, onipotente e incondicionado, de modo que não teria nenhum compromisso com a ordem vigente anteriormente à ruptura estabelecida pela nova Constituição.

Miranda (1996) entende que existem limites materiais ao poder constituinte originário, que caracteriza como transcendentes, valores éticos superiores emanados de uma consciência coletiva, como a dignidade da pessoa humana, valores relacionados à soberania do Estado, e valores heterônomos, decorrentes da relação com outros Estados.

Entendimento semelhante é defendido por Grau (2011, p. 44), segundo o qual o legislador não é livre para criar o direito posto (direito positivo), estando condicionado pelo direito pressuposto, que "brota da (na) sociedade, à margem da vontade individual dos homens". No raciocínio do autor, "o direito pressuposto condiciona a elaboração do direito posto, mas este modifica o direito pressuposto."

O poder constituinte, limitado ou ilimitado, é o poder que funda uma nova ordem jurídica, tendo elevado grau de liberdade criativa como expressão máxima da vontade e soberania do povo, revelando-se sempre mais inovador a partir de grandes acontecimentos.

Após a Segunda Guerra Mundial, o movimento constitucional contemporâneo, caracterizado pela fundação do Estado Democrático de Direito, rompeu com o positivismo jurídico e outorgou um caráter inovador caracterizado por uma forte carga axiológica, iniciando o movimento denominado de pós-positivismo (STRECK, 2017).

A partir da ideia do constitucionalismo contemporâneo, tem-se que somente o povo é legitimado para estabelecer comandos à sociedade, havendo a caracterização dos poderes político e jurídico, sendo o primeiro livre de limites formais, o próprio autor da Constituição, e o segundo, inserido na norma, responsável pela reforma do texto constitucional (BONAVIDES, 2011). 
Hesse (1991, p. 7), principal expoente da teoria da força normativa da constituição, entende que a "norma constitucional não tem existência autônoma em face da realidade. A sua essência reside na sua vigência, ou seja, a situação por ela regulada pretende ser concretizada na realidade."

Em resumo, a partir do segundo pós-guerra a Constituição é fundada precipuamente em sua carga axiológica, superando-se o formalismo e relvando-se a substância do documento, momento em que há precedência da democracia e do Estado Democráticos de Direito.

Recentemente, mais precisamente no final do século XX, surge na América do Sul, tendo como principais expoentes a Venezuela e a Bolívia, um movimento denominado como Novo Constitucionalismo Latino-americano, que se identifica com as causas sociais e o redimensionamento jurídico em favor dos povos sonegados e de suas principais necessidades (MARTÍNEZ DALMAU; VICIANO PASTOR, 2010).

Esse novo movimento constitucional surge a partir da consciência de que os conceitos constitucionais eurocêntricos não podem ser simplesmente implantados e tomados como verdadeiros em um contexto social e político com características absolutamente diferentes, principalmente no que tange à igualdade do povo.

A compreensão acerca desse novo movimento constitucional parte necessariamente do entendimento do "mito da modernidade", onde a Europa constitui a si mesma como o centro do mundo. Segundo Dussel (1993), o movimento europeu de descoberta de novas terras a partir das grandes navegações deu origem a um movimento de conquista, colonização, modernização, civilização, como resultado do ego moderno.

Houve um processo de encobrimento do outro, onde “o 'conquistador' é o primeiro homem moderno ativo, prático, que impõe sua 'individualidade' violenta a outras pessoas, o Outro" (DUSSEL, 1993). Essa "conquista” é um processo militar, impositivo, que inclui o Outro como o "si-mesmo", subjugando-o, resultando na supressão da cultura, do costume e, por consequência, com o estabelecimento de nova cultura, de novos costumes, inclusive religiosos, demonizando as crenças do Outro (DUSSEL, 1993).

No Brasil, como em toda a América-Latina, a desigualdade e seletividade produzem sistemáticos e seculares processos de exclusão e vitimização, sobretudo em relação aos povos marginalizados, para os quais o direito não é acessível e somente está disponível para 
impingir punição e manutenção do sistema vigente (LIXA, FERRAZZO e FAGUNDES, 2020).

O resultado dessa colonização imposta é a herança de uma cultura jurídica europeia, conforme expõe Wolkmer (2011):

Não é por demais relevante lembrar que, na América Latina, tanto a cultura jurídica imposta pelas metrópoles ao longo do período colonial, quanto as instituições jurídicas formadas após o processo de independência (tribunais, codificações e constituições) derivam da tradição legal europeia, representada, no âmbito privado, pelas fontes clássicas dos Direitos romano, germânico e canônico. Igualmente, na formação da cultura jurídica e do processo de constitucionalização latino-americanos pós-independência, há de se ter em conta a herança das cartas políticas burguesas e dos princípios iluministas inerentes às declarações de direitos, bem como provenientes agora da nova modernidade capitalista, de livre mercado, pautada na tolerância e no perfil liberal-individualista.

Especificamente no Brasil, esse processo de herança da cultura jurídica eurocêntrica resulta incialmente o domínio político-econômico das oligarquias agro-exportadoras, e, em seguida, a imposição do monismo jurídico a partir de sistemas constitucionais não democráticos, com manutenção do monismo jurídico através de alianças conservadoras. $\mathrm{O}$ pluralismo cultural e jurídico passa a ser embrionariamente reconhecido somente na Constituição Federal de 1988, importante instrumento de propulsão desse novo movimento constitucional (WOLKMER, 2011).

O Novo Constitucionalismo Latino-Americano se estabelece a partir dos fundamentos da democracia e do pluralismo jurídico, este que, segundo Wolkmer (1997, p. 205), pode ser conceituado como "a multiplicidade de práticas jurídicas existentes num mesmo espaço sócio-político, interagidas por conflitos ou consensos, podendo ser ou não oficiais e tendo sua razão de ser nas necessidades existenciais, materiais e culturais".

Esse movimento constitucional passa a defender uma filosofia libertadora, de emancipação do sistema jurídico e reconhecimento da pluralidade existente nos países colonizados, sugerindo a valorização das minorias culturais e das maiorias economicamente marginalizadas.

\section{A TENSÃO ENTRE CONSTITUCIONALISMO E DEMOCRACIA}


Democracia e constitucionalismo parecem conceitos contraditórios, pois democracia remete à ideia de soberania popular e constitucionalismo teoriza a existência de normas de natureza superior, fundantes do sistema jurídico, algumas, inclusive, que não admitem revogação.

A Constituição Federal de 1988, denominada de Constituição cidadã, é expressão da retomada da democracia no Brasil, pois não partiu de um projeto prévio, sendo pensada a partir da assembleia constituinte formada por deputados e senadores de treze partidos eleitos democraticamente, com intensa participação da sociedade civil através do envio de propostas (BRASIL, 2018).

O momento histórico evidenciava a importância da democracia, de modo que o art. $1^{\circ}$ da Constituição Federal estabelece os princípios da república e do federalismo e institui o Estado Democrático de Direito, ratificando a democracia no parágrafo único, segundo o qual "Todo o poder emana do povo, que o exerce por meio de representantes eleitos ou diretamente, nos termos desta Constituição" (BRASIL, 1988).

A referida norma institui um conceito complexo de democracia, que não pode ser entendido pelo simples pensamento de "governo pelo povo", tendo em vista que traz elementos do exercício direto e indireto do poder pelo povo, mas, principalmente, a necessidade de o poder ser exercido nos termos da Constituição.

A ideia de exercício indireto do poder remete ao conceito de democracia representativa, aquela exercida por um parlamentar eleito diretamente pelos cidadãos aptos a votar. Segundo Mill apud Kierecz (2016), é importante a escolha de um representante com conhecimento apropriado e em condições de defender posições perante o parlamento, havendo o controle pelo povo através da pressão direta e do instituto da reeleição.

Entretanto, esse controle através de pressão e pelo instituto da reeleição parece ter perdido força, de modo que "verifica-se uma certa subordinação da população a vários interesses econômicos e pessoais, de quem controla a circulação da riqueza ou de quem detém parcelas do poder" (KIERECZ, 2016).

Segundo Carvalho (apud Kierecz, 2016),

O eleitor vota no deputado em troca de promessas e favores pessoais; o deputado apoia o governo em troca de cargos e verbas para distribuir entre seus eleitores. Cria-se uma esquizofrenia política: os eleitores desprezam os políticos, mas continuam votando neles na esperança de benefícios pessoais. 
Visões como esta, de falência do sistema representativo, acabaram por acarretar nas recentes manifestações do Dia da Independência do Brasil (7/09/2021), onde os grupos de apoiadores do Presidente Jair Messias Bolsonaro pretendiam a intervenção do Executivo nos Poderes Legislativo e Judiciário, além de outras pautas secundárias com fortes ideias nacionalistas e religiosos.

Mesmo com a aparente frustação das pretensões da parcela da população que foi às ruas para defender as referidas pautas, é relevante a análise de que a manifestação ganhava roupagem democrática com a invocação do art. $1^{\mathrm{o}}$ da Constituição Federal, sendo visíveis várias faixas com dizeres como "todo o poder emana do povo".

Entretanto, conforme dito acima, a leitura correta é mais complexa: "Todo o poder emana do povo, que o exerce por meio de representantes eleitos ou diretamente, nos termos desta Constituição" (BRASIL, 1988). Assim, a democracia deve ser exercida nos termos e limites da própria Constituição.

É neste contexto que surge a questão chave do presente trabalho: considerando eventos como o do último 7/09/2021, em que parcela relevante da população foi às ruas pleiteando medidas aparentemente inconstitucionais, pergunta-se se democracia e constitucionalismo são conceitos antagônicos ou complementares?

Para Matteucci (1998, p. 257),

[...] a democracia foi definida como Governo da maioria; mas, se essa maioria tivesse um poder absoluto e ilimitado, ela poderia subverter as regras do jogo e destruir assim as próprias bases da democracia, coisa sempre possível, se pensarmos que, em um grande Estado, a própria representatividade, ao limitar o princípio democrático, acarreta o perigo de que a vontade da maioria dos deputados não se ajuste sempre à vontade da maioria dos eleitores. Por conseguinte, hoje o Constitucionalismo não é outra coisa senão o modo concreto como se aplica e realiza o sistema democrático representativo.

Dworkin (1995), tem contribuição que se apresenta relevante na busca da resposta ao questionamento, defendendo que a concepção majoritária de democracia é insuficiente, sendo necessário adotar a concepção comunitária, segundo a qual se constrói a noção de povo como entidade distinta e não exclusivamente como mero agrupamento de indivíduos, sendo necessária a efetiva participação de todos o processo decisório.

Além disso, não haverá democracia quando o governo negar as regras constitucionais (regras do jogo) anteriormente estabelecidas, negar a legitimação de seus oponentes, tolerar 
ou encorajar a violência e ter propensão a restrição das liberdades civis (LEVITSKY e ZIBLATT, 2018).

Nessa esteira, o conceito de democracia está diretamente ligado à observância das normas constitucionais, havendo ampla abertura e legitimação para os interessados na participação do processo eleitoral, intolerância da violência como meio de expressão popular e garantia de ampla liberdade ao povo.

Defende-se também a necessária existência de normas de tolerância mútua e reserva institucional, querendo dizer com isso que é imprescindível que todos os participantes do jogo democrático sejam ouvidos e respeitados e que haja um eficiente sistema de freios e contrapesos entre os poderes (LEVITSKY e ZIBLATT, 2018).

Nem sempre o povo é capaz de garantir a prevalência da democracia, pois, através de falácias, demagogos autoritários podem tomar o poder e subverter o regime democrático. Por isso, entende-se que os partidos políticos são importantes "filtros", que podem evitar que líderes antidemocráticos assumam e permaneçam no poder (LEVITSKY e ZIBLATT, 2018).

Além disso, os modelos de democracia e constitucionalismo importados da Europa são insuficientes para atender satisfatoriamente as demandas sociais latino-americanas, tendo em vista que as promessas do constitucionalismo esbarram na ausência de políticas públicas capazes de efetivar os direitos, criando um descontentamento popular (LIXA, FERRAZZO e FAGUNDES, 2020).

\section{CONSIDERAÇÕES FINAIS}

O presente trabalho foi elaborado com o objetivo de analisar a possível tensão entre constitucionalismo e democracia, o que se fez a partir da abordagem teórica de autores clássicos e contemporâneos e da análise de um caso concreto, o movimento do dia sete de setembro de 2021, quando o Presidente da República, Jair Messias Bolsonaro, conclamou a população para ir às ruas em seu apoio, havendo manifestações em prol da intervenção nos poderes legislativo e judiciário, mudança no processo eleitoral etc.

A hipótese inicial é de que inexiste contradição entre constitucionalismo e democracia, mas complementação. Para a verificação da hipótese analisou-se o conceito de constitucionalismo e democracia desde a revolução francesa, passando pelo segundo pósguerra até os tempos atuais. 
As revoluções iluministas e ascensão da burguesia buscavam no constitucionalismo e na democracia a limitação dos poderes do monarca, a separação dos poderes e uma participação popular no processo eleitoral, o que ocorria com exclusão de grande parte da população.

Após a Segunda Guerra Mundial, os direitos sociais e a dignidade da pessoa humana foram destaques no constitucionalismo, que adentrou na fase do pós-positivismo, onde a Constituição pode até mesmo representar um freio à vontade da maioria para fazer preservar os direitos fundamentais pressupostos da condição humana.

Contemporaneamente, o movimento chamado de Novo Constitucionalismo LatinoAmericano sugere a análise do direito e da democracia a partir de uma visão pluralista, tecendo interessantes considerações sobre um movimento revolucionário de decolonialização e estabelecimento de uma nova visão de democracia, que se desvincula de um paradigma representativo e busca a efetivação da vontade popular, com a pretensão de estabelecer a efetiva libertação das minorias marginalizadas, que passam a participar efetivamente das decisões políticas.

Essa releitura do constitucionalismo preocupa-se em repensar a simples importação de conceitos políticos e jurídicos da Europa. O direito de igualdade sob os prismas sociais da Europa e da América do Sul, por exemplo, parte de premissas absolutamente diferentes, tendo em vista que o povo sul-americano é descendente de uma histórica cruel, de marginalização das minorias e de controle político pelas elites, sem que o eleitorado tenha o acesso necessário a educação para entender que seu voto não tem preço e que este é o principal meio de exercício da democracia.

Nesse sentido, parece correto afirmar que o constitucionalismo instrumentaliza a democracia, pois estabelece princípios sem os quais não seria possível o exercício da soberania do povo e, ao mesmo tempo, a defesa das minorias. Parece que um termômetro para medir se a democracia está presente é verificar se a minoria tem condições de se tornar maioria, e, mesmo sendo minoria, tenha seus direitos fundamentais garantidos pela maioria.

Em resumo, o presente trabalho conduz ao entendimento de que a democracia está ligada ao conceito de igualdade e de respeito às regras do jogo estabelecidas na Constituição, pressupondo-se a participação do povo na tomada de decisões, votos com valor idêntico, uma agenda política que respeite a vontade popular e a inclusão do maior número de pessoas no 
processo eleitoral, de modo que os conceitos de democracia e constituição estão intimamente correlacionados.

\section{REFERÊNCIAS BIBLIOGRÁFICAS}

BARCELlOS, Ana Paula. Curso de direito constitucional.3. Rio de Janeiro : Forense, 2020. 1 recurso online. Disponível em: https://integrada.minhabiblioteca.com.br/books/9788530989774. Acesso em: 19 set. 2021.

BARROSO, Luís Roberto. Curso de direito constitucional contemporâneo: os conceitos fundamentais e a construção do novo modelo. 9. ed. São Paulo: Saraiva, 2019.

BRASIL. Constituição (1988). Constituição da República Federativa do Brasil. Brasília, DF: Senado Federal: Centro Gráfico, 1988.

BRASIL. O Brasil em construção: 30 anos da Constituição Cidadã. Câmara dos Deputados, Brasília, 20 out. 2018. Disponível em:https://www2.camara.leg.br/acamara/visiteacamara/cultura-na-camara/atividades-anteriores/exposicoes-2018/o-brasil-emconstrucao-30-anos-da-constituicao-cidada. Acesso em 21 out. 2021.

BOBBIO, Norberto; MATTEUCCI, Nicola; PASQUINO, Gianfranco. Dicionário de política. 5. ed. Brasília: Editora Universidade de Brasília, 1998. v. 1.

BONAVIDES, Paulo. Curso de Direito Constitucional. 26. ed. São Paulo: Malheiros, 2011.

CANOTILHO, J. J. Gomes. Direito constitucional. Coimbra: Almedina, 1993.

CANOTILHO, J.J.Gomes. Direito Constitucional e Teoria da Constituição. 6. ed. Coimbra - Portugal: Livraria Almedina, 2002.

DUSSEL, Enrique. 1492, O Encobrimento do Outro: a origem do mito da modernidade. Petrópolis: Vozes, 1993.

DWORKIN, Ronald. Constitucionalismo e democracia. Tradução de Emílio Peluso Neder Meyer. European JOurnal oh Philosophy, v. 3, n. 1, p. 2-11, 1995.

KIERECZ, Marlon Silvestre. A crise da democracia representativa no Brasil. In Cadernos do Programa de Pós Graduação em Direito. V. XI n. 2, 2016. P. 360-385. Porto Alegre.

GRAU, Eros Roberto. O Direito posto e o Direito pressuposto. 8. ed. São Paulo: Malheiros, 2011.

HABERMAS, Jurgen. Direito e democracia: entre facticidade e validade. Rio de Janeiro: Tempo Brasileiro, 1997. nv. (Biblioteca tempo universitário, 101-102). Tradução de: Faktizitat und Geltung. 
LAKATOS, Eva Maria; MARCONI, Marina de Andrade. Fundamentos de metodologia científica. São Paulo: Atlas, 1991.

LEVITSKY, Steven, ZIBLATT, Daniel. Como as democracias morrem. Tradução: Renato Aguiar. 1 ed. São Paulo: Zahar, 2018.

LIXA, Ivone F. M.; FERRAZZO, Débora; FAGUNDES, Lucas F. Cultura jurídica lanitoamericana: Entre o pluralismo e o monismo na condição da colonialidade. San Luis Potosi: Cenejus-UASLP, 2020.

KELSEN, Hans. A Democracia. 2. ed. São Paulo: Martins Fontes, 2000.

MARTÍNEZ DALMAU, Rúben; VICIANO PASTOR, Roberto. Aspectos generales del nuevo constitucionalismo latino-americano. In: El nuevo constitucionalismo en América Latina: memorias del encuentro internacional el nuevo constitucionalismo: desafíos e retos para el siglo XXI. Corte Constitucional del Ecuador, Quito, 2010, p. 9-44.

MIRANDA, Jorge. Manual de direito constitucional. Tomo II. 3 ed. Portugal, Coimbra, 1996.

ROUSSEAU, Jean-Jacques. Considerações sobre o Governo da Polônia e sua reforma projetada. Trad. Luiz Roberto Salinas Fortes. São Paulo: Brasiliense,1982.

ROUSSEAU, Jean-Jacques. Discurso sobre a origem e os fundamentos da desigualdade entre os homens. Trad. de Iracema Gomes Soares e Maria Cristina Nagle. Brasília: Básica Universitária / SãoPaulo: Ática, 1989.

STRECK, Lênio L. Dicionário de hermenêutica: quarenta temas fundamentais da teoria do direito à luz da crítica hermenêutica do Direito. Belo Horizonte (MG): Letramento, 2017.

WOLKMER, Antônio Carlos; FERRAZZO, Daniela (2020). Uma abordagem descolonial sobre democracia e cultura jurídica na modernidade. Revista Brasileira De Estudos Políticos, 120. Disponível em: https://doi.org/10.9732/rbep.v120i0.607. Acesso em 20 abr 2021.

WOLKMER, Antônio Carlos. Pluralismo e Crítica do Constitucionalismo na América Latina. In Anais do [Recurso eletrônico] IX Simpósio de Direito Constitucional da ABDConst. - Curitiba, PR : ABDConst., 2011.

WOLKMER, Antônio Carlos. Pluralismo jurídico: fundamentos de uma nova cultura do direito. 2. ed. São Paulo: Alfa-Omega, 1997. 